\title{
Cryptosporidium spp. and Giardia duodenalis: A picture in Portugal
}

\author{
André Silva Almeida ${ }^{1,2}$, Sónia Cristina Soares², \\ Maria Lurdes Delgadoㄹ, Elisabete Magalhães Silva², \\ António Oliveira Castro ${ }^{1}$ and José Manuel Correia da Costa ${ }^{1}$ \\ ${ }^{1}$ Center for Parasite Immunology and Biology, CSPGF-INSA, Porto \\ ${ }^{2}$ Center for the Study of Animal Science, CECA-ICETA, Porto \\ Portugal
}

\section{Introduction}

Cryptosporidium is an entero-pathogen which causes gastrointestinal disturbs. Primarily this organism infects the microvillous border of the intestinal epithelium, and to lesser extent extra intestinal epithelia, causing acute gastrointestinal disturbs (Fayer, 2004). The duration of infection and the ultimate outcome of intestinal cryptosporidiosis greatly depend on the immune status of the patient. In fact, immunologically healthy patients usually recover spontaneously in a week. The clinical signs can range from asymptomatic to acute, severe and persistent diarrhea and their potential for Cryptosporidium transmission can persist for weeks after symptoms cease (Deng et al., 2004; Fayer, 2004; Hunter and Thompson, 2005).

Similar to Cryptosporidium, Giardia is an entero-pathogen, but a non-cell-invasive which causes giardiasis. The most prominent clinical signs of the disease are abdominal pain, nausea, followed by severe watery diarrhea, dehydration, malabsorption (particularly lipids and lipid soluble vitamins) and weight loss. Chronic courses are characterized by recurrent brief or persistent episodes of diarrhoea (Eckmann and Gillin, 2001; Muller and von Allmen, 2005).

Due to some particular biological features, Cryptosporidium and Giardia represent an important question of environmental contamination with impact for human and animal health. These are single-celled organisms that belong to the kingdom Protista, and are common food and waterborne protozoa that affect humans and a wide range of domestic and wild animals (Fayer, 2004). They have a low infection dose necessary to infect humans, with possible as few as 10 organisms in some cases (USDA). They have emerged in the last two decades as intriguing microbes with an enormous impact in Animal (including wildlife species) and Human Health, potentiated by the environmental contamination of the infectious stages. Both can cause mild to severe diarrhea. No specific therapy has proven to be effective, but immunocompetent individuals generally recover within a week (USDA). However, immunocompromised individuals may be unable to clear the parasites and, therefore, suffer chronic and debilitating illness. They have been recognized as important pathogens in contaminated drinking water, meaning a problem of environmental contamination, due to two main reasons pointed out: 1) their resistance and biological 
viability under conventional drinking water treatment conditions (chlorination and filtration); 2) the occurrence of cryptosporidiosis and giardiasis outbreaks associated with the consumption of contaminated water. This was the case in an outbreak in Milwaukee (Wisconsin, USA) in 1993, the largest waterborne disease outbreak reported all over the World. An estimated 400,000 people were reported ill (USDA).

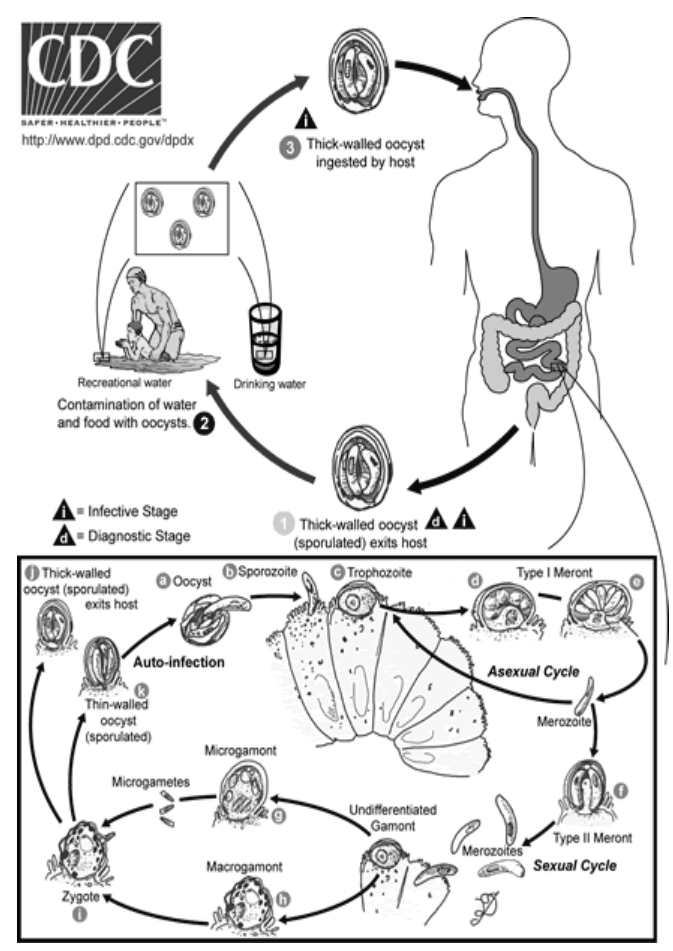

Fig. 1. Life cycle of Cryptosporidium paroum or Cryptosporidium hominis . From CDC (www.cdc.gov).

The life cycle of Cryptosporidium comprises an asexual stage and sexual stage; Cryptosporidium has a spore phase named oocyst, which represents the infectious stage of Cryptosporidium and is the resistant form found in the environmental; the oocyst is extraordinary resistant to common disinfectants of water, such as chloride, and the water represents the primary transmission route (Figure 1). The infection begins with the ingestion of oocysts through contaminated water or food, or by fecal-oral contact. After ingestion, the excystation of oocyst is induced by the acidic nature of stomachic lumen and the presence of enzymes. However, this event occurs in the small intestine favored by the presence of the neutral $\mathrm{pH}$, bile salts and fatty acids. Each oocyst contains four sporozoites. They are released and try immediately to infect epithelial cells of the gastrointestinal tract. At the end of this endogenous cycle, sporulated oocysts are formed which, once shed in the environment with feces, are ready to infect a new suitable host. The prepatent period, which means the time between the ingestion of infecting oocysts and the excretion of a new generation of oocysts, varies with the host and species of Cryptosporidium, but usually it 
ranges from 4 to 22 days. The patent period, which means the duration of oocyst excretion, ranges from 1 to 20 days. As previously stated, transmission of Cryptosporidium may occur through contact with contaminated water and food. In fact, many reported outbreaks occurred in water parks, pools and day care centers.

The life cycle of Giardia is monoxenic, and comprises two stages: the cyst and the trophozoite (Figure 2). The cysts are the resistant form and are approximately 7 to $10 \mu \mathrm{m}$ length and oval in shape; cysts can be found in feces and are released into the environment where they can survive and remain viable for several months in cool or moist conditions. They are responsible for disease transmission, and they are able to survive under the standard concentrations of chlorine used in water treatment plants. The infection occurs after ingestion of cysts in contaminated water, food, or by the fecal-oral route in the absence of hygienic conditions. The excystation of cysts is induced by the acidic nature of stomachic lumen and the presence of enzymes. However, this event occurs in the small intestine favored by the presence of the neutral $\mathrm{pH}$, and bile salts and fatty acids. Each cyst contains two trophozoites. Trophozoites have two distinct nuclei, four pairs of flagellae, are 12 to 15 $\mu \mathrm{m}$ length. They multiply by asexual reproduction, longitudinal binary fission, and colonize the lumen of the proximal small bowel, attaching to the mucosa of the bowel using a ventral sucking disk. Trophozoites are responsible for the clinical disease in the host. Cysts are excreted in the feces and became immediately infectious, making possible the transmission from person-to-person (http://www.dpd.cdc.gov/dpdx/HTML/Giardiasis.htm). The prepatent period varies with the host and species of Giardia, with a median value of 14 days.

Giardia and Cryptosporidium share common characteristics that influence greatly the epidemiology of their infections. They are maintained in a variety of transmission cycles, independently, not requiring interaction between them (Figure 3). Giardia can be maintained in independent cycles involving wildlife or domestic animals, and similarly, Cryptosporidium can be maintained in cycles involving livestock, especially cattle. As observed in Figure 3, the circumstances under which such cycles may interact and where zoonotic transfer occurs are not completely understood (Hunter and Thompson, 2005). Cysts and oocysts are the stage transmitted from an infected host to a susceptible host by the fecal-oral route. Several common transmission routes exist, and include a) person-to-person through direct or indirect contact, where sexual activities may potentiate transmission, b) from animal-toanimal, c) animal-to-human, d) water-borne through drinking water and recreational water, and, e) food-borne (Caccio and Ryan, 2008; Caccio et al., 2005; Fayer et al., 2000; Hunter and Thompson, 2005). The infected hosts, whether human or animals, shed very large numbers of transmissive stages (oocysts and cysts) in their faeces, thereby increasing environmental contamination. The infective dose of both parasites, in human infections, was calculated taking into account statistical data and experimental infection studies: the ID50 varies regarding the isolates, ranging from 9 to 1042 oocysts for Cryptosporidium and 1 to 10 cysts for Giardia (Adam, 2001; Fayer et al., 2000; Okhuysen et al., 1999). These features markedly influence the epidemiology of these infections: a) the infective dose is low for both parasites; b) cysts and oocysts are immediately infectious when excreted in faeces, and possess several transmission routes; c) cysts and oocysts are very stable and can survive for weeks to months in the environment; d) water and food may became contaminated due to the environmental dispersal. The transmission of these infections, either direct or indirect, is favored by several factors such as high population densities and close contact with infected hosts or contaminated water or food. These factors are dependent on the infecting species, 
either in zoonotic and anthroponotic transmissions. Recent studies suggested separated risks for $C$. hominis (such as travel abroad and contact with infected diarrheic individuals) and C. parvum (contact with cattle) (Caccio et al., 2005; Hunter et al., 2004). In sporadic cryptosporidiosis, risk factors include the age of patients (children under five years of age), travelling, contact with infected individuals and contact with farm animals (Caccio et al., 2005). Furthermore, swimming in public swimming pools or recreational areas represents a risk of infection, as suggested by Australian and US studies (Robertson et al., 2002; Roy et al., 2004). Curiously, authors have postulated that, although Cryptosporidium is transmitted through contaminated food, a small number of parasites in these samples may not induce infection with clinical symptoms but a protective immunity (Meinhardt et al., 1996).

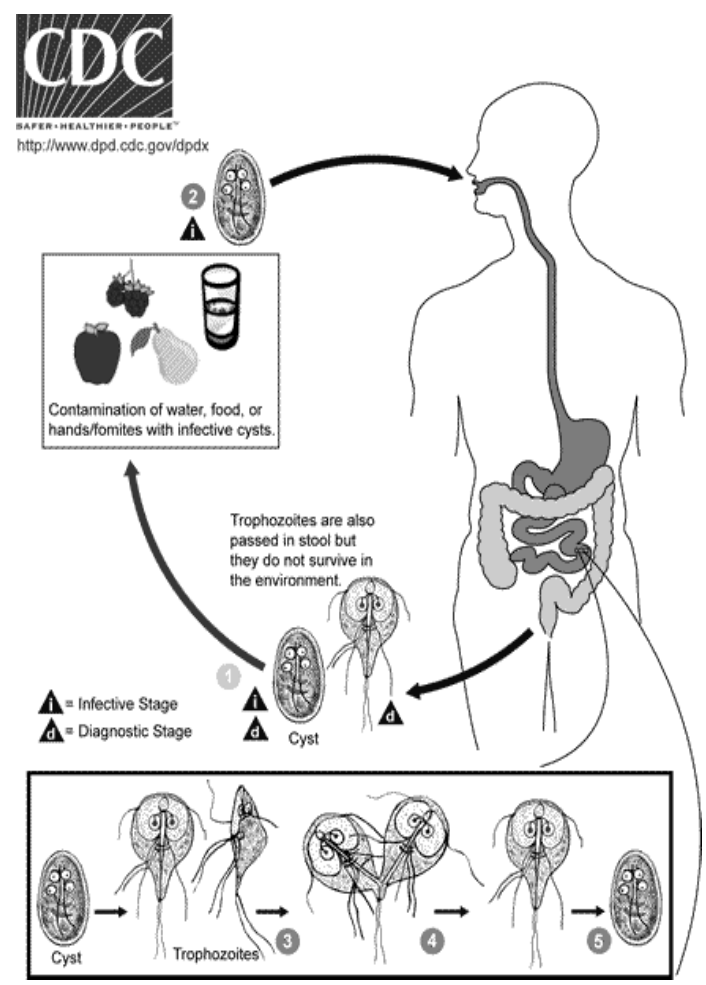

Fig. 2. Life cycle of Giardia duodenalis. From CDC (www.cdc.gov).

There are no requirements for testing surface waters for the presence of these parasites, although analyses of outbreaks have shown that the pathogens can be shed into recreational waters (Castro-Hermida et al., 2008). Also, similar studies regarding Giardia transmission and sporadic giardiasis performed by authors in UK, reveled as main risks the swallowing of water while swimming, drinking treated tap water, contact with fresh water and easting lettuce (Stuart et al., 2003). The introduction of molecular tools analysis on the epidemiological field can produce useful information allowing to a better understanding about the origin of contamination, the genetic characterization of involved species/genotype/assemblage and their zoonotic potential: a new field in the modern molecular epidemiology. 
The taxonomic and filogenetic relationships of Cryptosporidium and Giardia remain poorly defined; thus, the understanding of their transmission dynamics has been limited. A consensus has been adopted: with molecular techniques, the ability to observe extensive genetic variation within Cryptosporidium and Giardia species is leading to a better understanding of the taxonomy and zoonotic potential of these variants, and the epidemiology of the diseases. Namely, genotyping of samples using molecular analysis at informative loci is necessary to distinguish species and genotypes that are involved and their zoonotic potential.

These molecular tools have been helpful to enhance our knowledge and understanding of the taxonomy, host range and transmission routes of Cryptosporidium and Giardia and the epidemiology of human disease. Moreover, these tools are used to understand the public health importance of different environmental routes of transmission, leading toward improved strategies for prevention and surveillance of cryptosporidiosis and giardiasis (Fayer et al., 2000; Jex et al., 2008; Monis and Thompson, 2003; Smith et al., 2006). Some methods rely on the specific in situ hybridization of probes to particular genetic loci within Cryptosporidium oocysts and Giardia cysts, whereas the majority relies on the specific amplification of one or more loci from small amounts of genomic DNA by polymerase chain reaction (PCR). This is particularly helpful in the environmental samples or others where the parasite load is low (Jex et al., 2008; Smith et al., 2006).

The present chapter presents a long term study performed in Portugal aiming to assess the prevalence of two Protozoan parasites, Cryptosporidium spp. and Giardia duodenalis, in surface raw water and drinking water samples, and assess the risk that this microbial environmental contamination poses for human and animal health. The study was guided by a multidisciplinary team comprising several Veterinarians, researchers and technicians, and developed in the North region of Portugal. A long term program was established aiming at pinpointing the sources of surface water, drinking water, and environmental contamination, working with the water-supply industry. This program comprised the collection of raw and treated water samples in previously defined areas by using the Method 1623, described by the Environmental Protection Agency (US - EPA).

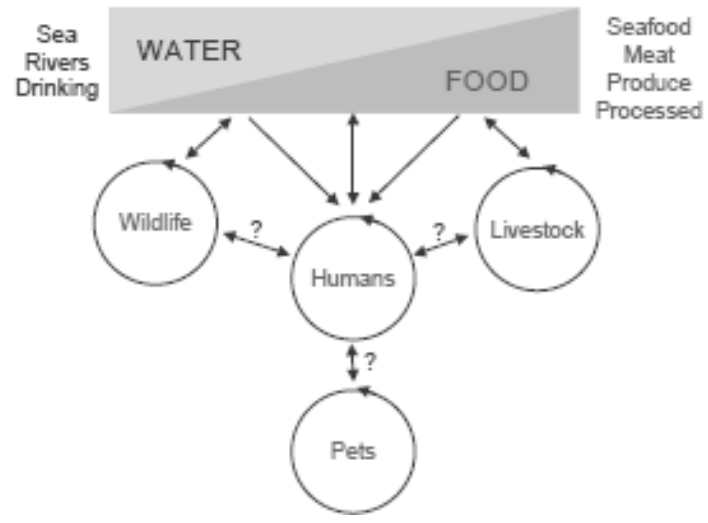

Fig. 3. The most important cycles of transmission for maintaining Giardia and Cryptosporidium. Besides direct transmission, water and food may also play a role in transmission. The frequency of interaction between cycles is not known. From (Hunter and Thompson, 2005) 


\section{Material and methods}

In the north of Portugal there are 5 major hydrographical basins forming the most important water resources of the country. These hydrographical basins are named after the main rivers; Minho, Lima, Cávado, Ave, and Douro (Figure 4,5). Cávado and Ave rivers run entirely inside national (Portuguese) borders, while Minho, Lima, and Douro are international rivers, with sources in Spain. Global features of the area, based on data provided by CCDRN, are as follows: The resident population in 2006 is 3,744,341 inhabitants; animal husbandry is an important economic activity; there are poorly developed sanitation infrastructures with wastewater plants discharging into these hydrographical basins; $64 \%$ of resident population has access to sanitation and $84 \%$ has access to treated drinking water; the region has the highest population density of the country, reaching 176 inhabitants per $\mathrm{km}^{2}$, there are a high number of recreational areas, river beaches as well as pumping areas for drinking water plants.

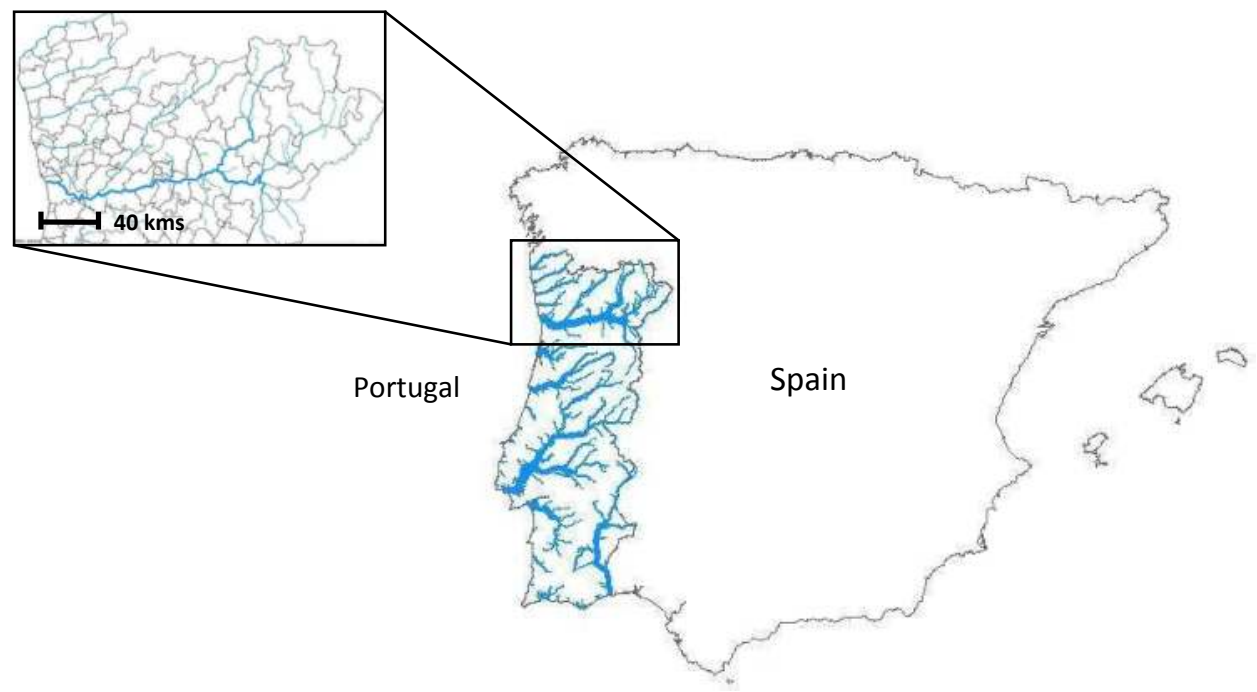

Fig. 4. Geographic location of the North of Portugal and its 5 hydrographical basins into Iberian Peninsula

\section{Water sample collection}

\section{Raw water collection}

Raw water samples were collected twice a year between January 2004 to December 2006 from 97 sources, including main rivers and respective affluents, from upriver to downriver. The volume of each sample ranged from 25 to $100 \mathrm{~L}$. Samples were filtered through FiltaMax filters (IDEXX Laboratories, Inc., Westbrook, Maine, USA) with a pump on the inlet side of the filter according to the recommendation of the manufacturer. Intact filters were kept in refrigerated containers and transported immediately to the laboratory. The filter was taken from the container and processed with the aid of a Filta-Max Manual Wash Station (IDEXX Laboratories, Inc.) for further elution and concentration process, which consisted of 
decompression of the filter, passing the sample through a membrane, and centrifugation. A sample pellet (around $2 \mathrm{ml}$ ) was obtained and transferred to a Leighton tube for subsequent immunomagnetic separation (IMS).

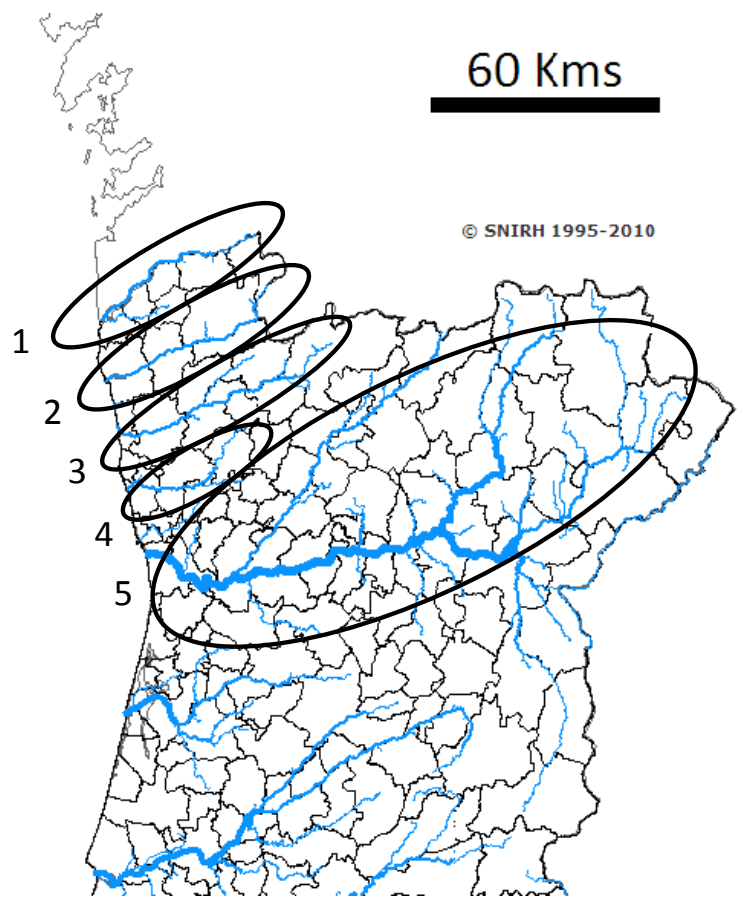

Fig. 5. Location of the 5 hydrographical basins in the North of Portugal. 1. Minho; 2. Lima; 3. Cávado; 4. Ave; 5. Douro

\section{Drinking water collection}

As previously described for raw water, drinking water samples were collected twice a year from January 2004 to December 2006 in 43 sampling points in the drinking water treatment plants, from upriver to downriver, from all the 5 hydrographical basins (Figure 4 and 5). Always as possible, drinking water sampling points were derived from the previous related raw water collection points. This was not always possible due to legal impositions from the water supply companies. The volume of each sample ranged from 80 to $100 \mathrm{~L}$. Samples were collected locally, filtered through Filta-Max filters (IDEXX Laboratories, Inc., Westbrook, ME, USA) as previously described for raw water processing.

\section{Parasite detection}

The IMS procedure was performed according to the USEPA method 1623 [USEPA]. Briefly, anti-Giardia and anti-Cryptosporidium magnetic beads were mixed with SL Buffer A and SL Buffer B in each Leighton tube containing the sample concentrate (Dynabeads GC-Combo, Invitrogen Dynal, A. S., Oslo, Norway) and incubated $1 \mathrm{hr}$ at room temperature. Then, using 2 magnetic particle concentrators, beads were collected, washed, and transferred into a 1.5 
$\mathrm{ml}$ tube. Fifty- $\mu \mathrm{l}$ of $0.1 \mathrm{~N} \mathrm{HCl}$ were added to each sample to dissociate beads from the target organisms, the beads were rejected, and the suspension was transferred to the wells of the slides containing $5 \mu \mathrm{l}$ of $1.0 \mathrm{~N} \mathrm{NaOH}$. The samples were air-dried overnight and stained with FITC-conjugated anti-Cryptosporidium spp. and anti-Giardia spp. monoclonal antibodies, according the manufacturer's instructions (Crypto/Giardia Cells, Cellabs, Australia). The excess of FITC-mAb was removed by adding $100 \mu \mathrm{l}$ of PBS to each well, leaving the slides for $5 \mathrm{~min}$, and aspirating the excess of PBS. A $50-\mu \mathrm{l}$ aliquot of $4^{\prime}-6^{\prime}-$ diamino-2-phenylindole (DAPI) solution $(0.4 \mathrm{mg} / \mathrm{ml}$ in PBS) was introduced into each well. The slides were left at room temperature for $15 \mathrm{~min}$, and excess DAPI solution removed by washing the slides in PBS. Slides were examined by epifluorescence microscope. Giardia cysts and Cryptosporidium oocysts were indentified and counted based on their shape and size using a Nikon Optiphot fluorescence microscope (Nikon Corporation, Tokyo, Japan). The number of cysts and oocysts per each well was recorded and concentrations extrapolated per $10 \mathrm{~L}$ of sample. Positive and negative controls were performed as indicated by the manufacturer and recommended in the Method 1623. The mean recovery percentages of oocysts of Cryptosporidium spp. and cysts of Giardia spp. using the Filta-Max system and IMS procedures from water samples is, according to the manufacturer, $50 \pm 13 \%$ and $41 \pm$ $79 \%$, respectively (McCuin and Clancy, 2003).

\section{DNA extraction, PCR and sequencing}

PCR analysis was performed in the samples with the highest density of infectious stages of both parasites detected by DFA. The criterion utilized was the detection of a minimum of 50 cysts/oocysts of any parasite in the total sample volume. In this context, the genetic characterization was executed in 80 samples derived from raw water and 4 samples derived from treated drinking water. The cover slip was separated from the slide and with the aid of cotton swab soaked with $100 \mu \mathrm{l}$ of distillated water, the surface of the slide was scraped in order to collect the sample. It was confirmed, under microscope observation that the slide had no remaining cysts or oocysts. The tip of the cotton swab was cut and placed in a $1.5 \mathrm{ml}$ tube for subsequent DNA extraction with a QIAamp DNA Mini Kit (QIAGEN GmbH, Hilden, Germany), according to the manufacturer's instructions.

For determining the species of Cryptosporidium and Giardia present in the samples, PCR analyses were performed. A 2-step nested PCR was performed to amplify a portion of the small subunit (SSU) ribosomal RNA gene of Cryptosporidium spp. (Xiao et al., 1999). For the molecular typing of Giardia spp., a semi-nested PCR was performed to amplify a portion of the b-giardin gene (Caccio et al., 2002). For all PCR reactions, negative and positive controls were prepared, with sterile water and reference DNA, respectively. The PCR products were analyzed in agarose gel $(1.4 \%)$ stained with ethidium bromide under UV light. Images were captured with a gel documentation system (GelDoc2000, BioRad, Hercules, California, USA). The PCR products of the successful reaction were purified by Wizard SV Gel and PCR Clean-up System (Promega, Madison, Wisconsin, USA) and sequenced in both strands by an external laboratory (EUROFINS MWG OPERON, Ebersberg, Germany). Chromatograms were examined with the software ChromasPro (http://www.technelysium.com.au/ ChromasPro.html) and the sequences with the software ProSeq (http://www.biology.ed.ac.uk/ research/institutes/evolution/software/filatov/ proseq.htm). Sequences were compared with the GenBank database with the tool BLAST (http://blast.ncbi.nlm.nih.gov/Blast.cgi) and deposited in the database Zoop-Net of the Med-Vet-Net network (http://www. medvetnet.org). 


\section{Results}

IMS and DFA detection of infectious stages of Cryptosporidium spp. and G. duodenalis in raw and drinking water samples

The number of validated raw water samples in this study was 283 . Environmental stages of the protozoa were detected in $72.8 \%$ (206 of 283) of the water samples, including $15.2 \%$ (43 of 283) positive for cysts of G. duodenalis, 9.5\% (27 of 283) for oocysts of Cryptosporidium spp., and 48.1\% (136 of 283) for both parasites (Table 1). In Figure 6, the percentages of positive and negative samples from the 5 hydrographical basins are shown individually. The Ave basin showed the highest percentage of positive samples; $90.2 \%$ of the samples were positive. Minho basin showed the lowest percentage of positive samples, even though this value was more than $64 \%$. In all the 5 hydrographic basins, the co-presence of Cryptosporidium and Giardia counted for the majority of positive samples, with the exception of Minho basin in which Giardia positive samples were slightly more than Cryptosporidium and Giardia positive samples. In the cases where both parasites were present in the same sample, the number of $G$. duodenalis cysts always outnumbered Cryptosporidium spp. oocysts. We also found no correlation between the concentrations of both parasites, meaning that, when the concentration of Giardia cysts is high, Cryptosporidium oocysts are not necessarily high (data not shown). Furthermore, the range of the concentrations of $G$. duodenalis cysts was much higher than Cryptosporidium spp. oocysts $(0.17-50,000$ cysts per $10 \mathrm{~L}$ and $0.2-726.1$ oocysts per $10 \mathrm{~L}$, respectively). In positive water samples, no empty (i.e., without internal characteristics, or ghosts) or DAPI negative Cryptosporidium spp. oocysts or G. duodenalis cysts were found. In all cases, it was possible to observe an increase of parasite load from upriver to downriver. The majority of water samples from the international rivers (Minho, Lima, and Douro) collected at the border with Spain was negative.

\begin{tabular}{|c|c|c|c|c|c|c|c|c|c|c|}
\hline & Positive & $\%$ & Cryptosporidium & $\%$ & Giardia & $\%$ & $\begin{array}{c}\text { Cryptosporidium } \\
\text { and Giardia }\end{array}$ & $\%$ & Total & $\%$ \\
\hline Raw water & 206 & 72,8 & 27 & 9,5 & 43 & 15,2 & 136 & 48,1 & 283 & 100,0 \\
\hline Drinking water & 43 & 25,7 & 17 & 10,2 & 14 & 8,4 & 12 & 7,2 & 167 & 100 \\
\hline
\end{tabular}

Table 1. Overall prevalence of infectious stages of Cryptosporidium spp. and Giardia duodenalis in raw and drinking water samples collected.

Similar to this, the number of validated drinking water samples in this study was 167. In Figure 6 the percentage and concentration of isolates from the 5 hydrographical basins are shown. Negative results, for both protozoa, were obtained in 124 out of 167 drinking water samples. Infectious stages of the protozoa were detected in $25.7 \%$ (43 out of 167) of the water samples. Among them, 8.4\% (14 out of 167) of the samples were with cysts of Giardia, 10.2\% (17 out of 167) with oocysts of Cryptosporidium, and 7.2\% (12 out of 167) with both parasites (Table 1). In positive water samples, no empty (i.e., without internal characteristics, or ghosts) or DAPI negative oocysts of Cryptosporidium spp. or cysts of G. duodenalis were found. Furthermore, the mean concentrations of $G$. duodenalis cysts were much higher than those of the Cryptosporidium spp. oocysts (0.1-108.3 cysts per $10 \mathrm{~L}$ and $0.1-12.7$ oocysts per 10 $\mathrm{L}$, respectively). 


\begin{tabular}{|c|c|c|c|c|}
\hline Sample & Sampling site & $\begin{array}{l}\text { Number of oocysts (C) } \\
\text { and cysts }(G) \text { detected }\end{array}$ & $\begin{array}{c}\text { Giardia duodenalis } \\
\text { assemblages }\end{array}$ & $\begin{array}{l}\text { Cryptosponidium } \\
\text { species }\end{array}$ \\
\hline $51 \mathrm{~B}$ & Ponte do Bico R. Homem & $398 G-334 C$ & & C. andersoni \\
\hline $53 \mathrm{~B}$ & Ribeira de Panoias & $25000 G-35 C$ & $A-1 \& B$ & C. andersoni \\
\hline $55 \mathrm{~B}$ & Ribeira de pontes Barcelos & $511 \mathrm{G}-1955 \mathrm{C}$ & & C.andersoni \\
\hline $56 \mathrm{~B}$ & Jusante Etar de Barcelos & $11,000 G-96 C$ & & C. andersoni \\
\hline $58 \mathrm{~B}$ & Foz do Cávado-Barca do Lago & $5754 G-98 C$ & & C. andersoni \\
\hline $60 \mathrm{~B}$ & Eta Areias de vilar r. Cávado & $2313 G-32 C$ & $A-11$ & C. hominis \\
\hline $66 \mathrm{~B}$ & Rio Selho Pte Brandão & $6590 \mathrm{G}-90 \mathrm{C}$ & A-II & \\
\hline $67 \mathrm{~B}$ & Foz do Vizela/Rebordōes & $2178 G-46 C$ & $B$ & C. andersoni \\
\hline $68 \mathrm{~B}$ & Ponte da Trofa/R Ave & $2146 G-1211 C$ & $A \& B \& E$ & C. andersoni \\
\hline $69 B$ & Ponte do Ave/R Ave & $1022 G-84 C$ & $A \& B \& E$ & C. andersoni \\
\hline $70 \mathrm{~B}$ & Foz do R Este/Arcos/Vila Conde & $855 G-262 C$ & A-II & C. andersoni \\
\hline $79 \mathrm{~B}$ & Eta de Ferreira & $5396 \mathrm{G}-44 \mathrm{C}$ & $A-11$ & C. andersoni \\
\hline $80 \mathrm{~B}$ & Albufeira Alto Cávado & $221 G-37 C$ & & C. parvum \\
\hline $98 \mathrm{~B}$ & Foz do Sabor/Cabeça boa & $233 G-16 C$ & & C. parvum \\
\hline $105 B$ & Foz do Sousa-Gondomar & $1192 G-33 C$ & & C. andersoni \\
\hline $132 \mathrm{~B}$ & Ponte do Bico R. Homem-Bruta & $526 \mathrm{G}-11 \mathrm{C}$ & & C. andersoni \\
\hline $139 \mathrm{~B}$ & Jusante Etar de Barcelos & $1101 G-4 C$ & & C. andersoni \\
\hline $141 B$ & Foz do Cávado-Barca do Lago & $686 G-13 C$ & & C. andersoni \\
\hline $147 \mathrm{~B}$ & Ponte do Ave/R Ave & $1,131 G-56 C$ & & C. andersoni \\
\hline $148 B$ & Foz do R Este/Arcos/Vila Conde & $449 G-494 C$ & & C. andersoni \\
\hline $154 \mathrm{~B}$ & Ponte do Brandāo-Rib do Selho & $5128 G-229 C$ & & C. muris \\
\hline
\end{tabular}

Table 2. Results of genetic characterization of Cryptosporidium spp. and Giardia duodenalis and the respective number of cysts and oocysts (same table was published in Almeida et al. Korean J Parasitol 2010; 48:91-95).

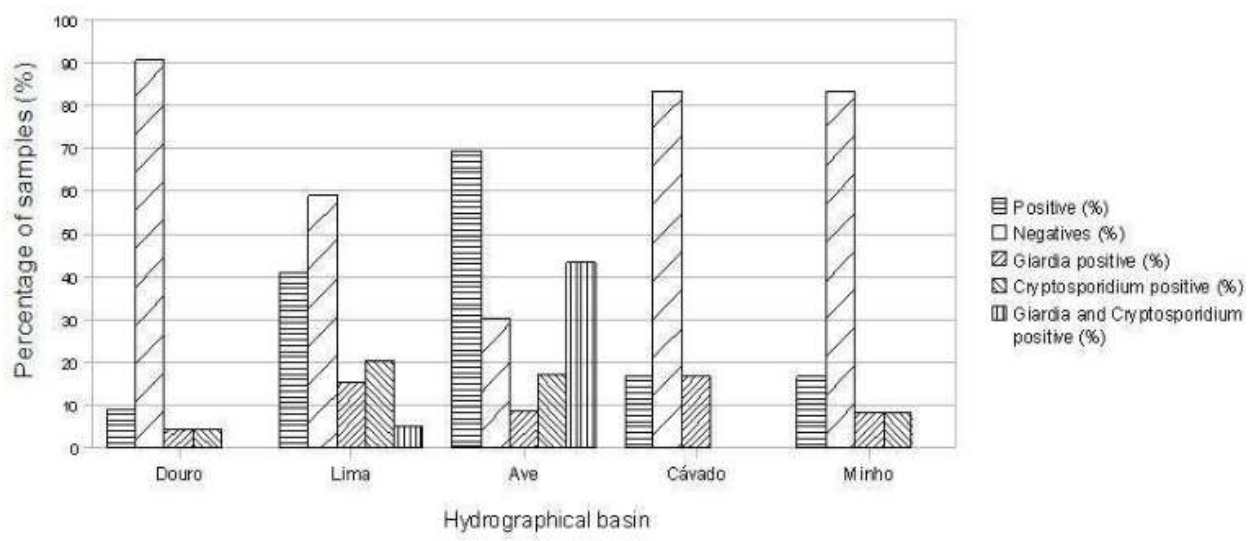

Fig. 6. Distribution of the results obtained by Method 1623 EPA-USA for infectious stages of Cryptosporidium spp. and Giardia duodenalis in drinking water samples collected in the 5 hydrographical basins (same figure was published in Almeida et al. Korean J Parasitol 2010; 48:165-169). It is shown the percentage of positive or negative samples per hydrograpical basin.

\section{Genetic characterization of species and genotypes isolated}

By PCR, it was unable to amplify DNA extracted from slides containing less than 50 oocysts of Cryptosporidium and 50 cysts of Giardia. Furthermore, positive amplifications over 3 
replicates were never obtained when the number of cysts and oocysts was less than 1,000 per slide. With this criterion, of all the positive IMS samples from raw and drinking water, PCR amplification was performed over 80 samples and 4 samples derived from drinking water. Of referring that in these drinking water samples, the PCR was not successful and no amplification was obtained. In raw water samples, genetic characterization was successful in 8 samples for G. duodenalis and 20 samples for Cryptosporidium spp. In 59 samples, PCR amplification was not successful. A summary of the PCR results is shown in Table 2. Cryptosporidium andersoni was found in 16 samples, Cryptosporidium paroum in 2 samples, Cryptosporidium hominis in 1 sample, and Cryptosporidium muris in 1 sample. G. duodenalis assemblage A-II was found in 4 samples, assemblage B in 1 sample, and in the remaining 3 samples assemblages A, B, and E were found. Although it was not possible to obtain positive PCR results in treated water, it is expected that at the end of the treatment process the same species and genotypes will be found.

\section{Discussion}

The results of the present study indicate that the infectious stages of Cryptosporidium spp. and G. duodenalis are widely distributed in the rivers of northern Portugal in very significant concentrations. Also, it is observed that drinking water for human consumption is produced in very efficient plants regarding the elimination of these parasites.

The region has a high density of livestock farms favoring the cycle of parasite amplification. Surface waters (rivers, reservoirs, canals, and low land reservoirs) are used to produce drinking water for human consumption, and some of the raw water collection points presented in this work are the same collection points of the water industry for drinking water production. The surface water collected from the rivers is used as drinking water for the animals or used for agricultural purposes, by the majority of farmers, the feces are directly released into the rivers or reach it by runoff waters. The environmental contamination in these conditions is greater, as the contamination of husbandry. In fact, has been shown in a previous study a prevalence of $25 \%$ of Cryptosporidium infections in 467 bovine fecal samples in northern Portugal (Mendonca et al., 2007). Producers must be advertized about the risk of infection for both protozoa, and the low efficiency in animal production. It is very likely that these are the reasons why it was observed a considerable prevalence of these parasites in surface water, although the drinking water for human consumption derived from it has a low prevalence of these parasites: it is produced in very efficient plants of water industry. In the great majority of raw water samples it was observed contamination by Cryptosporidium or Giardia (72,8 \%), but in the drinking water this number was quite low $(25,7 \%)$. Furthermore, in the positive samples, the parasite load was largely lower than the infectious dose.

Systematic studies on the genetic characterization of both protozoans indicate that the genus Cryptosporidium includes species that are infective for humans only (anthroponotic), humans and animals (zoonotic), and other pathogenic species that are not infective for humans (Fayer). Also, several G. duodenalis genotypes are infective to humans (zoonotic genotypes), and others are non-pathogenic (Caccio and Ryan, 2008). Amplification and sequencing of genes 18S SSU rRNA for Cryptosporidium spp. and b-giardin for G. duodenalis has been used to identify the zoonotic species and genotypes of the parasites (Hunter and Thompson, 2005; Read et al., 2004). Obviously, it is largely recognized that there is lack of consensus about 
genetic markers for the correct assignment of the species and subspecies of Cryptosporidium and Giardia. The gene markers (18S SSU rRNA and b-giardin) are generally accepted as good markers mainly because they are multicopy genes (18S SSU rRNA), restricted to these parasites (b-giardin), and with fixed differences among Cryptosporidium and Giardia species and subspecies (both genes). In the present study, in an attempt to produce relevant and comparable results, the choice of 18S SSU rRNA and b-giardin genes, frequently used by the most recognized researchers, was considered.

C. paroum (zoonotic) and C. hominis (anthroponotic) are the most common human-infecting species reported in river water samples in Europe, and C. andersoni is the animal-infecting species (Castro-Hermida et al., 2008; Xiao and Fayer, 2008). The same studies indicated G. duodenalis assemblage $\mathrm{A}$ as the most common zoonotic genotype, and $\mathrm{G}$. duodenalis assemblage $\mathrm{E}$ as the most common non-zoonotic genotype (Almeida et al., 2006a; Caccio et al., 2003; Castro-Hermida et al., 2008; Sousa et al., 2006; Xiao and Fayer, 2008).

Our results suggest that the contamination of the surface waters in the north of Portugal is highly significant. We have found the zoonotic species of the genus Cryptosporidium described by other authors (Lobo et al., 2009). In addition, there was higher concentration of G. duodenalis detected by genotyping, with a greater genetic diversity. Assemblage A was found in 7 PCR positive samples (1 A-I and 6 A-II). The presence of the assemblage A-I has been suggested as an indicator of water contamination by livestock, while assemblage A-II has been considered a potential indicator of water contamination by humans (Almeida et al., 2006a; Caccio and Ryan, 2008). Nevertheless, in the northern part of the country assemblage A-I have been found in human samples (Sousa et al., 2006), and assemblage A-II in bovine samples (Castro-Hermida et al., 2007; Mendonca et al., 2007). Also, G. duodenalis assemblage $\mathrm{B}$ was detected in 4 of 8 samples. Assemblage B has been reported as a zoonotic genotype. The presence of infectious stages of this genotype in water samples has been attributed to water contamination by humans (Caccio and Ryan, 2008). Assemblage E was detected in 2 samples associated with assemblage A and B, suggesting a mixed human and animal source of contamination.

C. parvum was detected in 2 of the 20 processed samples. This species has a great zoonotic potential, and may have an animal or human source of contamination. A few studies concerning the biological reservoir (human and bovine) in the north of Portugal have indicated C. paroum as an important pathogen infecting the great majority of bovines as well as immunocompromised human patients (Almeida et al., 2006a; Almeida et al., 2006b; Mendonca et al., 2007). Recent data suggest that subgenotyping tools may generate more information about the zoonotic potential of C. parvum isolates, although there is still lack of evidences on the usefulness of the generated data for risk assessment (Fayer). C. hominis, considered an anthroponotic (human restricted) species, was detected in 1 sample. This species was also reported in water samples and in human stool samples from Portugal (Almeida et al., 2006a; Almeida et al., 2006b; Alves et al., 2003; Lobo et al., 2009). C. andersoni, a strictly bovine pathogen, was detected in 16 samples; C. muris was detected in only 1 sample suggesting water contamination by rodents.

Curiously, as previously mentioned, no PCR amplification was obtained in drinking water samples. Sensitivity tests were set in the laboratory for the PCR reactions, and the number of 50 cysts or oocysts was our limit of sensitivity. For this reason, the great majority of drinking 
water samples, with lower parasite load, were out of selection for PCR amplification. Furthermore in the remaining samples subject to PCR, subjected to DNA extraction and PCR, the amplification did not occur. This was also true for a great amount of raw water samples subjected to molecular analysis: 59 samples. This problem has been described by other authors (Jiang et al., 2005), and the most reasonable reason maybe the presence of inhibitor of the polymerase, which was not tested in the present approach or that sufficient amounts of DNA may not be present (empty oocysts or cysts after excystation). Our sensitivity analysis indicates simultaneously a lack of reproducibility in the PCR analysis and the difficulty to achieve amplification in samples with low levels of contamination. The IMS procedure applied over the samples for parasite isolation does not guarantee a complete purity of the sample. Thus, optimization of DNA extraction and amplification protocols is warranted.

The results of this study seem to indicate that the risk assessment for cryptosporidiosis and giardiasis for humans is low in the north of Portugal. However, for this, the condition that whole population has access to the network system for drinking water needs to be fulfilled, and, in this case, this condition is not observed for a very significant segment of the northern population. First of all, according to the national statistics, only $84 \%$ of the population has access to the drinking water system; second, among the population covered by the drinking water distribution systems (84\%), a significant segment are provided by water obtained in wells or other origin. Old habits, water prices, and lack of information about the quality of the treated water are the main reasons referred. Taking into account these aspects and the real number of people consuming water for the drinking water systems supply, it is expected that one third of the northern Portuguese population is exposed to the infection by Cryptosporidium and Giardia due to consumption of water. Thus, systematic monitoring of drinking water, livestock, and human biological samples are needed for risk assessment of both diseases. National Health Authorities should consider the urgent implementation of a national monitoring program for microbiological quality of drinking water that includes Cryptosporidium spp. and G. duodenalis analyses. These activities are fundamental steps to understand better the epidemiology of the infection and to allow the implementation of risk analysis models for those infections.

\section{Acknowledgments}

This work was financially supported by funds of Project 61018, Action Environment and Health, from Calouste Gulbenkian Foundation, and funds of Project PTDC/CVT/103081/2008 from Portuguese Foundation for Science and Technology (FCT).

\section{References}

Adam, R.D., 2001, Biology of Giardia lamblia. Clin Microbiol Rev 14, 447-475.

Almeida, A.A., Delgado, M.L., Soares, S.C., Castro, A.O., Moreira, M.J., Mendonca, C.M., Canada, N.B., Da Costa, J.M., 2006a, Genotype analysis of Giardia isolated from asymptomatic children in northern Portugal. J Eukaryot Microbiol 53 Suppl 1, S177178. 
Almeida, A.A., Delgado, M.L., Soares, S.C., Castro, A.O., Moreira, M.J., Mendonca, C.M., Canada, N.B., Da Costa, J.M., Coelho, H.G., 2006b, Genetic characterization of Cryptosporidium isolates from humans in northern Portugal. J Eukaryot Microbiol 53 Suppl 1, S26-27.

Alves, M., Xiao, L., Sulaiman, I., Lal, A.A., Matos, O., Antunes, F., 2003, Subgenotype analysis of Cryptosporidium isolates from humans, cattle, and zoo ruminants in Portugal. J Clin Microbiol 41, 2744-2747.

Caccio, S.M., De Giacomo, M., Aulicino, F.A., Pozio, E., 2003, Giardia cysts in wastewater treatment plants in Italy. Appl Environ Microbiol 69, 3393-3398.

Caccio, S.M., De Giacomo, M., Pozio, E., 2002, Sequence analysis of the beta-giardin gene and development of a polymerase chain reaction-restriction fragment length polymorphism assay to genotype Giardia duodenalis cysts from human faecal samples. Int J Parasitol 32, 1023-1030.

Caccio, S.M., Ryan, U., 2008, Molecular epidemiology of giardiasis. Mol Biochem Parasitol $160,75-80$.

Caccio, S.M., Thompson, R.C., McLauchlin, J., Smith, H.V., 2005, Unravelling Cryptosporidium and Giardia epidemiology. Trends Parasitol 21, 430-437.

Castro-Hermida, J.A., Almeida, A., Gonzalez-Warleta, M., Correia da Costa, J.M., Rumbo-Lorenzo, C., Mezo, M., 2007, Occurrence of Cryptosporidium parvum and Giardia duodenalis in healthy adult domestic ruminants. Parasitol Res 101, 14431448.

Castro-Hermida, J.A., Garcia-Presedo, I., Almeida, A., Gonzalez-Warleta, M., Correia Da Costa, J.M., Mezo, M., 2008, Contribution of treated wastewater to the contamination of recreational river areas with Cryptosporidium spp. and Giardia duodenalis. Water Res 42, 3528-3538.

Deng, M., Rutherford, M.S., Abrahamsen, M.S., 2004, Host intestinal epithelial response to Cryptosporidium parvum. Adv Drug Deliv Rev 56, 869-884.

Eckmann, L., Gillin, F.D., 2001, Microbes and microbial toxins: paradigms for microbialmucosal interactions I. Pathophysiological aspects of enteric infections with the lumen-dwelling protozoan pathogen Giardia lamblia. Am J Physiol Gastrointest Liver Physiol 280, G1-6.

Fayer, R., Taxonomy and species delimitation in Cryptosporidium. Exp Parasitol 124, 9097.

Fayer, R., 2004, Cryptosporidium: a water-borne zoonotic parasite. Vet Parasitol 126, 3756.

Fayer, R., Morgan, U., Upton, S.J., 2000, Epidemiology of Cryptosporidium: transmission, detection and identification. Int J Parasitol 30, 1305-1322.

Hunter, P.R., Hughes, S., Woodhouse, S., Syed, Q., Verlander, N.Q., Chalmers, R.M., Morgan, K., Nichols, G., Beeching, N., Osborn, K., 2004, Sporadic cryptosporidiosis case-control study with genotyping. Emerg Infect Dis 10, 1241-1249.

Hunter, P.R., Thompson, R.C., 2005, The zoonotic transmission of Giardia and Cryptosporidium. Int J Parasitol 35, 1181-1190.

Jex, A.R., Smith, H.V., Monis, P.T., Campbell, B.E., Gasser, R.B., 2008, Cryptosporidium-biotechnological advances in the detection, diagnosis and analysis of genetic variation. Biotechnol Adv 26, 304-317. 
Jiang, J., Alderisio, K.A., Singh, A., Xiao, L., 2005, Development of procedures for direct extraction of Cryptosporidium DNA from water concentrates and for relief of PCR inhibitors. Appl Environ Microbiol 71, 1135-1141.

Lobo, M.L., Xiao, L., Antunes, F., Matos, O., 2009, Occurrence of Cryptosporidium and Giardia genotypes and subtypes in raw and treated water in Portugal. Lett Appl Microbiol 48, 732-737.

McCuin, R.M., Clancy, J.L., 2003, Modifications to United States Environmental Protection Agency methods 1622 and 1623 for detection of Cryptosporidium oocysts and Giardia cysts in water. Appl Environ Microbiol 69, 267-274.

Meinhardt, P.L., Casemore, D.P., Miller, K.B., 1996, Epidemiologic aspects of human cryptosporidiosis and the role of waterborne transmission. Epidemiol Rev 18, 118136.

Mendonca, C., Almeida, A., Castro, A., de Lurdes Delgado, M., Soares, S., da Costa, J.M., Canada, N., 2007, Molecular characterization of Cryptosporidium and Giardia isolates from cattle from Portugal. Vet Parasitol 147, 47-50.

Monis, P.T., Thompson, R.C., 2003, Cryptosporidium and Giardia-zoonoses: fact or fiction? Infect Genet Evol 3, 233-244.

Muller, N., von Allmen, N., 2005, Recent insights into the mucosal reactions associated with Giardia lamblia infections. Int J Parasitol 35, 1339-1347.

Okhuysen, P.C., Chappell, C.L., Crabb, J.H., Sterling, C.R., DuPont, H.L., 1999, Virulence of three distinct Cryptosporidium parvum isolates for healthy adults. J Infect Dis 180, 1275-1281.

Read, C.M., Monis, P.T., Thompson, R.C., 2004, Discrimination of all genotypes of Giardia duodenalis at the glutamate dehydrogenase locus using PCR-RFLP. Infect Genet Evol 4, 125-130.

Robertson, B., Sinclair, M.I., Forbes, A.B., Veitch, M., Kirk, M., Cunliffe, D., Willis, J., Fairley, C.K., 2002, Case-control studies of sporadic cryptosporidiosis in Melbourne and Adelaide, Australia. Epidemiol Infect 128, 419-431.

Roy, S.L., DeLong, S.M., Stenzel, S.A., Shiferaw, B., Roberts, J.M., Khalakdina, A., Marcus, R., Segler, S.D., Shah, D.D., Thomas, S., Vugia, D.J., Zansky, S.M., Dietz, V., Beach, M.J., 2004, Risk factors for sporadic cryptosporidiosis among immunocompetent persons in the United States from 1999 to 2001. J Clin Microbiol 42, 2944-2951.

Smith, H.V., Caccio, S.M., Tait, A., McLauchlin, J., Thompson, R.C., 2006, Tools for investigating the environmental transmission of Cryptosporidium and Giardia infections in humans. Trends Parasitol 22, 160-167.

Sousa, M.C., Morais, J.B., Machado, J.E., Poiares-da-Silva, J., 2006, Genotyping of Giardia lamblia human isolates from Portugal by PCR-RFLP and sequencing. J Eukaryot Microbiol 53 Suppl 1, S174-176.

Stuart, J.M., Orr, H.J., Warburton, F.G., Jeyakanth, S., Pugh, C., Morris, I., Sarangi, J., Nichols, G., 2003, Risk factors for sporadic giardiasis: a case-control study in southwestern England. Emerg Infect Dis 9, 229-233.

Xiao, L., Fayer, R., 2008, Molecular characterisation of species and genotypes of Cryptosporidium and Giardia and assessment of zoonotic transmission. Int J Parasitol 38, 1239-1255. 
Xiao, L., Morgan, U.M., Limor, J., Escalante, A., Arrowood, M., Shulaw, W., Thompson, R.C., Fayer, R., Lal, A.A., 1999, Genetic diversity within Cryptosporidium parvum and related Cryptosporidium species. Appl Environ Microbiol 65, 3386-3391. 


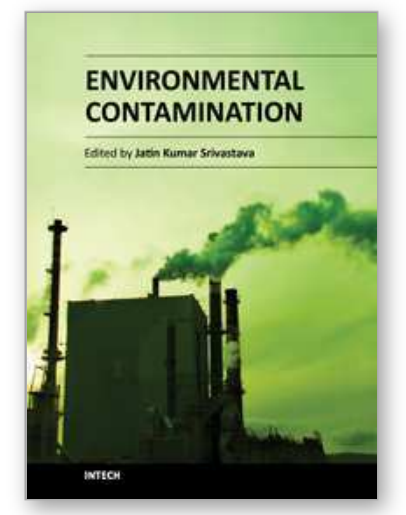

\author{
Environmental Contamination \\ Edited by Dr. Jatin Srivastava
}

ISBN 978-953-51-0120-8

Hard cover, 220 pages

Publisher InTech

Published online 29, February, 2012

Published in print edition February, 2012

Nature minimizes the hazards, while man maximizes them. This is not an assumption, but a basic idea of the findings of scientists from all over the world. The last two centuries have witnessed the indiscriminate development and overexploitation of natural resources by man causing alterations and impairment of our own environment. Environmental contamination is the result of the irrational use of resources at the wrong place and at the wrong time. Environmental contamination has changed the lifestyle of people virtually all over the world, and has reduced the extent of life on earth. Today, we are bound to compromises with such environmental conditions, which was not anticipated for the sustenance of humanity and other life forms. Let us find out the problem and its management within this book.

\title{
How to reference
}

In order to correctly reference this scholarly work, feel free to copy and paste the following:

André Silva Almeida, Sónia Cristina Soares, Maria Lurdes Delgado, Elisabete Magalhães Silva, António Oliveira Castro and José Manuel Correia da Costa (2012). Cryptosporidium spp. and Giardia duodenalis: A picture in Portugal, Environmental Contamination, Dr. Jatin Srivastava (Ed.), ISBN: 978-953-51-0120-8, InTech, Available from: http://www.intechopen.com/books/environmental-contamination/cryptosporidium-sppand-giardia-duodenalis-a-picture-in-portugal

\section{INTECH}

open science | open minds

\author{
InTech Europe \\ University Campus STeP Ri \\ Slavka Krautzeka 83/A \\ 51000 Rijeka, Croatia \\ Phone: +385 (51) 770447 \\ Fax: +385 (51) 686166 \\ www.intechopen.com
}

\author{
InTech China \\ Unit 405, Office Block, Hotel Equatorial Shanghai \\ No.65, Yan An Road (West), Shanghai, 200040, China \\ 中国上海市延安西路65号上海国际贵都大饭店办公楼 405 单元 \\ Phone: +86-21-62489820 \\ Fax: $+86-21-62489821$
}


(C) 2012 The Author(s). Licensee IntechOpen. This is an open access article distributed under the terms of the Creative Commons Attribution 3.0 License, which permits unrestricted use, distribution, and reproduction in any medium, provided the original work is properly cited. 